\title{
New from Old
}

\section{Dear Reader,}

Is it now right for the German government or a regional state to generally subsidise the cost of buying electric vehicles? Recent weeks have seen this issue become a hot talking point, both in the public sphere as well as among experts.

As already discussed in the MTZ worldwide 4/2016 editorial, however, it is not the type of drive - in other words combustion or electric engine - which dictates whether travel is $\mathrm{CO}_{2}$-neutral and excludes the use of fossil fuels, as both electricity and fuels can be obtained from either fossil-based or renewable energy sources.

If we leave aside charging or discharging losses for the moment, the high degree of efficiency - up to $99 \%$ sways the vote for e-drive vehicles. Arguments in favour of the combustion engine include its high range and the large quantities of energy that can be held per unit of time. Synthetic hydrogen-based fuels can also help to store excess electricity. In line with the slogan "conversion losses are preferable to upright wind turbines" - because grid capacity is insufficient and there is a lack of electrical storage facilities.

In this context, it should be in everyone's interest to seek a new basis for the debate about future drive systems with the general public. Combustion engines are not "old", any more than electric motors are "new" - in fact, quite the opposite. Moritz Jacobi had already developed an e-machine that was capable of propelling a boat as early as the 1830 s. As is generally known, it was not until a few decades later that gasoline and diesel engines came onto the scene.
Car makers and suppliers are in favour of refining charging and battery technology for electric vehicles. But there is also a wish to further boost combustion engine efficiency. The goal here is to make the best possible use of energy from renewable sources with all conceivable types of drive. There is no shortage of innovation in the combustion engine field, as our cover story amply demonstrates. Both Audi and Mazda show the need to rethink the downsizing trend pursued to date in order to help unleash additional potential. In this respect, the Japanese manufacturer even draws a comprehensive comparison with regard to the overall carbon footprint compared to electric mobility and is convinced that the combustion engine will remain around for a long time to come.

Best wishes,

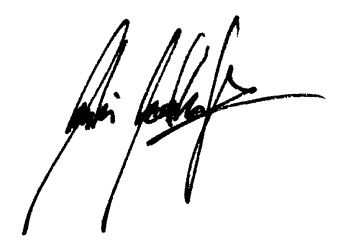

Dipl.-Journ. (FH) Martin Westerhoff Deputy Editor in Chief

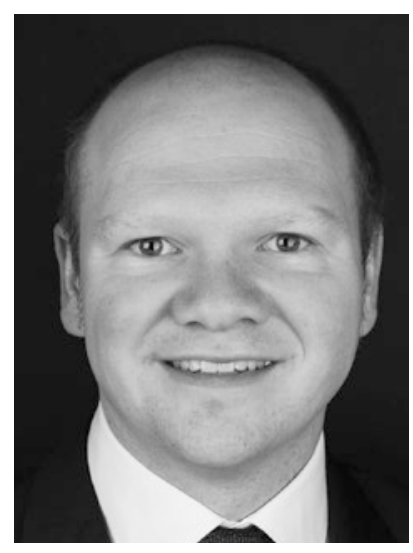

